\title{
Monitoring as an Information, Diagnostic, Scientific, and Prognostic System
}

\author{
Razumovskiy E.A. \\ Russian State University of Physical Education, Sport, \\ Youth and Tourism \\ Moscow, Russia. \\ evgazum@mail.ru
}

\author{
Mescheryakov A.V. \\ I.N. Ulyanov State Pedagogical University \\ Ulyanovsk, Russia \\ aleksei236632@yandex.ru
}

\author{
Nazarenko L.D. \\ I.N. Ulyanov State Pedagogical University \\ Ulyanovsk, Russia \\ ld_nazarenko@mail.ru
}

\begin{abstract}
The uses of monitoring are extremely diverse. Numerous monitoring systems have some common characteristics, which makes it possible to talk about monitoring as an integral independent scientific and practical phenomenon, which is interdisciplinary in nature. Monitoring problems in all areas of its use are being solved simultaneously: at the level of their theoretical understanding and at the level of its practical implementation. The existence of a large number of different monitoring systems gives rise to the need for their certain ordering. We have attempted to classify existing monitoring systems on several grounds.
\end{abstract}

Keywords-monitoring; control; management; system; classification

\section{INTRODUCTION}

The result of an extra-class, to the achievement of which, ultimately, the training process is directed, is inconceivable without constant comprehensive control over the state of the athlete's body. It should be born in mind that due to individual genotypically determined features in different phases of training, the state of the body can vary over a wide range, one of the facets of which is pathology. For athletes to achieve the maximum possible sports results, it is necessary to have objective information about the comprehensive preparedness of each athlete and the correction of his training process in accordance with his condition. An important role in this is played by the process of scientific and methodological support (NMO) for training athletes [3].

According to scientists $[1,2-4,6,7,9-12]$, the management algorithm of highly qualified athletes training process should be built and based on:

- on the determination of individual pulse criteria for the intensity of the training load in accordance with the preparation period;
- on the determination of the nature of training and competitive loads based on the use of group average, standard and individual pulse criteria for the intensity of the load, determined in the conditions of training sessions according to the speed of movement and heart rate;

- on the analysis of load accounting data and the results of testing motor qualities;

- on the development of managerial decisions on the correction of training programs depending on the nature of the body's adaptation processes to physical activity.

Thus, it is possible to carry out effective management in the presence of information obtained during monitoring.

Monitoring is understood as an integrated system of regulated periodic observations, estimates and forecasts of changes in the state of an object with the aim of identifying negative changes and making recommendations for their elimination or weakening. The uses of monitoring are extremely diverse. The existence of a large number of different monitoring systems gives rise to the need for their certain ordering.

\section{LITERATURE REVIEW}

Monitoring can be considered as an informational, diagnostic, scientific, forecasting system, the implementation of which is carried out as part of management activities [8]. In interdisciplinary (physical-sports) relations, monitoring refers to the activities of various sports organizations in monitoring the fulfillment by organizations of their obligations in practical activities. Monitoring mechanisms can be of a different nature: these include, for example, units of the ministry of sports, sports federations and associations, educational and scientific structures, etc [5, 13]. Within the 
the forecasted situation begins to change. In addition, it changes objectively, under the influence of the forecast background factors. Since the object of research is moving into a new quality, for these reasons the "worked-out" forecast is not suitable for subsequent decisions, a new one is needed.

We have proposed additional monitoring principles (in italics):

1. Efficiency - should be expressed not so much in the receipt, processing of information, but in the efficiency of decision-making in critical situations.

2. Objectivity of information: information should reflect the real state of affairs

3. Relevance - relevance of the methods used to collect information to the monitoring objectives and means of its organization.

4. Adequacy - compliance of the means and methods used to obtain data with the goals and objectives of control.

5. Predictability - focus on the forecast, predict the future state of the studied object.

6. Scientific.

7. Consistency - validation verification of the expected relationship between the results of a particular methodology and indicators of other methods that measure similar characteristics.

8. Integrity - continuity of the triad monitoringexamination-management.

But at the same time, it is possible to talk about the monitoring-forecast-management triad, since examination is more a procedural concept.

9. Continuity - obligatory implementation of all stages of monitoring.

10. Comparability of data: the comparison is correct in the case of studying the same object on the basis of the same indicators.

11. Information transparency - a necessary condition for management effectiveness. All research and observation results should be accessible to managers (trainers, doctors, and athletes). Users must formulate their requirements when designing monitoring programs.

12. Priority of management - is a universal sign for monitoring in general, in the event that management will be considered in the broad sense of the word and will include the formation or impact on public consciousness.

Numerous monitoring systems have some common characteristics, which makes it possible to talk about monitoring as an integral independent scientific and practical phenomenon. Differences in the interpretation of the essence of monitoring, in the goal-setting and means of its implementation - reflect the specificity and level of monitoring problems development in each of its application areas.

\section{CONCLUSION}

The following conclusions can be drawn from the above review:

1. Monitoring objects are dynamic, are in constant development. They are subject to external influences, which predetermined criteria, building a "tree of optimal solutions" $[4,5]$. But, as soon as the decisions made are put into practice, 
[9] Meshcheryakov A.V., Zhevnerov V.A. Increasing the reserve capacity of athletes. Bulletin of the pedagogy of physical education and sport. 2016 1, pp. 12-22.

and pose a danger to the user with monitoring information.

2. The implementation of monitoring involves the organization of the object continuous monitoring as possible. The measure of constancy is determined by the characteristics of the object and resource capabilities.

3. The organization of monitoring involves the selection of reasonable indicators.

4. Monitoring implies the presence of the main, or one of the forecasting stages of an object development (state change).

5. Each specific monitoring system is focused on a specific consumer. These may be: a specific governing body (s), separate (usually social and professional) groups, society as a whole.

6. Existing monitoring systems can be classified on a number of grounds. These include:

- $\quad$ scope of application;

- funds used to collect baseline information;

- potential users;

- measuring instruments;

- methods of disseminating information;

- implementation time;

- breadth of coverage.

Thus, monitoring problems in all spheres of its use are solved simultaneously both at the level of their theoretical understanding and at the level of its practical implementation.

We believe that a sufficient amount of time and effort will be required for a complex multicomponent complex of various areas of biomedical knowledge to take its rightful place in the formation of individual methods for achieving extra-class results. And the resulting data would clearly fit into the general concept of training highly qualified athletes.

\section{References}

[1] Ahmetov, R.F. (2004) TrenazhernI kompleksi v sistemI pIdgotovki stribunIv u visotu visokogo klasu [The training complexes in the system of training jumpers in the height of the high class]. Pedagogy, psychology and medical-biological problems of physical education and sports, 1, pp. 251-257.

[2] Barchukova, G.V. and Laptev. A.I. (2017), «Evaluation of the cardiovascular system during the development of technical and tactical skills in individual-game sports (on the example of badminton and table tennis)», Actual problems and prospects for the development of individual-game sports: materials of the All-Russian Scientific Internet Conference February 6 - April 10, 2017, SCOLIPE, pp. 103-107.

[3] Barchukova, G.V. and Laptev, A.I. (2015), «Model characteristics for physical fitness of elite athletes in table tennis», Sports science bulletin, No. 2, pp. 57-62.

[4] Barchukova G.V., Laptev A.I. Management of training loading based on variational pulsometry data in the microcycle of athletes specialized in table tennis / Scientific notes of the University named after P. F. Lesgaft. - № 4(158) - pp. 2018.

[5] Bestuzhev-Lada I.V. Expert scenario and prognostic monitoring: principles of organization. Sociological studies. 1993, 8, pp. 100-104.

[6] Bouget M, Rouveix M, Michaux O, Pequignot JM, Filaire E. Relationships among training stress, mood and dehydroepiandrosterone sulphate/cortisol ratio in female cyclists. J Sports Sci 2006: 24 (12): pp. 1297-1302.

[7] Laptev, A.I. (2014), Comprehensive control and correction of aerobic and speed-strength capabilities of wrestlers-Deaflympians in the management of their physical training, dissertation, Moscow.

[8] Levushkin S.P., Meshcheryakov A.V. About scientific and methodological support for the training of highly qualified athletes in the framework of the integrated scientific groups work. Theory and practice of physical culture. 2018, 5 (961), pp. 43.
[10] Alexsandr S. Kuznetsov. Russian Professor's meeting. Russian Journal of Physical Education and Sport. 2019, 14(1), pp. 17-22. DOI: 10.14526/2070-4798-2019-14-1-18-24.

[11] Surmay Z.A. The essence and necessity of regions manageria monitoring at the present stage of development of Russia. Economic Science and Practice: Materials of the International Scientific Conference - Chita: Publishing House Young Scientist. 2012, pp. 172-175.

[12] Shaverskiy, V.K. (2009). BIomehanIchnI ergogennI zasobi v sistem pIdgotovki studentIv spetsIalnostI «FIzichne vihovannya» of the specialty "Physical education"]. Moloda sportivna nauka UkraYini, (13)4, pp. 204-208.

[13] Savoie F.A., Kenefick R.W., Ely B.R., Cheuvront S.N., Goulet E.D.B Effect of hypohydration on muscle endurance, strength, anaerobic power and capacity and vertical jumping ability: a metaanalysis // Sports Med. (Auckland, NZ). 2015. Vol. 45, № 8. pp. 1207-1227. doi: $10.1007 / \mathrm{s} 4027901503490$.

[14] Kellmann, M. (2010). Preventing overtraining in athletes in high-intensity sports and stress/recovery monitoring. Scandinavian Journal of Medicine \& Science in Sports, 20, 95-102. doi: 10.1111/j.1600-0838.2010.01192.x

[15] McCartney D., Desbrow B., Irwin C. The effect of fluid intake following dehydration on subsequent athletic and cognitive performance: a systematic review and metaanalysis // Sports Med Open. 2017. Vol. 3, № 1. P. 13. doi: 10.1186/s407980170079y. Epub 2017 Mar 18.

[16] O'Toole M.L., Douglas P.S., Laird R.H., Hiller W.D.B. Fluid and electrolyte status in athletes receiving medical care at an ultradistance triathlon // Clin. J. Sport Med. 1995. Vol. 5. P. 116-122. [Biomechanical ergogenic means in the system of preparation of students 